\title{
Inducible Nitric Oxide-Mediated Myocardial Apoptosis Contributes to Graft Failure during Acute Cardiac Allograft Rejection in Mice
}

\author{
Wataru TAKAHASHI, MD, Jun-ichi SUZUKI, MD, Atsushi IZAWA, MD, \\ Kei TAKAYAMA, BS, Satoshi YAMAZAKI, MD, \\ and Mitsuaki IsOBE, ${ }^{1} \mathrm{MD}$
}

\section{SUMMARY}

The mechanism through which nitric oxide (NO) mediates cardiac myocyte death during acute cardiac rejection has not been fully delineated. We sought to determine whether NO promotes myocardial apoptosis and contributes to graft failure during acute cardiac rejection in a murine model.

Heterotopic cardiac transplantation was performed from Balb / c $\left(\mathrm{H}-2^{\mathrm{d}}\right)$ to $\mathrm{C} 3 \mathrm{H} / \mathrm{He}$ mice $\left(\mathrm{H}-2^{\mathrm{k}}\right)$. Recipients were treated with aminoguanidine $(\mathrm{AG})$ at $400 \mathrm{mg} / \mathrm{kg}$ every day after surgery. As references, we used isografts in Balb/c mice with and without AG treatment (400 mg / kg / day). Graft survival, histological changes and serum NO levels were assessed. Intra-graft apoptosis was evaluated using a DNA fragmentation detection assay (TUNEL method) and DNA laddering.

Significant prolongation of graft survival was observed in allografts treated with AG in comparison with nontreated allografts. Serum NO levels, which peaked on day 7 in nontreated allografts, were significantly decreased in AG-treated allografts. AG treatment decreased the number of apoptotic cells and lowered the ratio of the apoptotic cardiac myocytes in contrast to that of the apoptotic infiltrating cells. DNA laddering was clearly detected in nontreated allografts but was suppressed in AG-treated allografts.

Inhibition of NO production by AG prolonged murine cardiac allograft survival. The decrease in intra-graft apoptotic activity paralleled histological improvement. Cardiac myocyte death which occurs through an apoptotic process mediated by NO contributes to graft failure during acute cardiac rejection. (Jpn Heart J 2000; 41: 493-506)

Key words: Nitric oxide, Cardiac transplantation, Apoptosis, Mouse

\begin{abstract}
ACUTE graft rejection is characterized by intense infiltration of inflammatory cells followed by a rapid, progressive loss of graft tissue. Large amounts of nitric oxide (NO) produced by inducible NO synthase (iNOS) have been implicated in cardiac myocyte damage and myocardial vascular dysfunction in acutely rejected

From the First Department of Internal Medicine, Shinshu University School of Medicine, Nagano and ${ }^{1}$ Department of Cardiovascular Medicine, Tokyo Medical and Dental University, Tokyo, Japan.

Address for correspondence: Mitsuaki Isobe, MD, Department of Cardiovascular Medicine, Tokyo Medical and Dental University, 1-5-45, Yushima, Bunkyo-ku, Tokyo 113-8519, Japan.

Received for publication January 12, 2000.

Revised and accepted April 20, 2000.


cardiac allografts. ${ }^{1-3)} \mathrm{NO}$ is synthesized by the oxidation of L-arginine catalyzed by NO synthase (NOS). ${ }^{4}$ Under basal conditions, endothelial constitutive NO synthase (cNOS) generates low concentrations of NO in response to sheer stress and cytokines, and regulates vessel tone, platelet aggregation and neutrophil adhesion to the vessel wall. ${ }^{4)}$ The oxidant injury is mediated by high levels of NO produced by iNOS over a prolonged period in macrophages, vascular smooth muscle cells and cardiac myocytes during inflammation, including acute cardiac rejection and myocarditis. ${ }^{5)}$ However, the immunoregulatory role of NO during acute rejection is controversial. For example, NO suppresses allospecific and non-specific T lymphocyte proliferation in cell cultures. ${ }^{6,7)}$ But treatment with iNOS inhibitor attenuates inflammatory infiltration in rejected allografts. ${ }^{8)}$ Recent studies have shown that NO produced by iNOS mediates apoptosis of macrophages and other cells. ${ }^{9-11)}$ Apoptosis of myocardial cells has been observed in rejecting allografts in parallel with the expression of iNOS. ${ }^{12,13)}$

The role of NO in apoptosis is also unclear. NO inhibits apoptosis of some kinds of human and animal cell lines induced by different stimuli, such as Fas and TNF- $\alpha,{ }^{14-16)}$ whereas NO has had a proapoptotic effect in other experimental models..$^{9-11)}$ Also, NO is a regulator of apoptosis as evidenced by the fact that cytokine-induced apoptosis of cardiac myocytes in cell culture was completely blocked by treatment with NOS inhibitor. ${ }^{17)}$

If NO promotes apoptosis of cardiac myocytes in rejecting cardiac grafts, it is possible that NO-mediated apoptosis contributes to graft failure during acute rejection. The experiments presented here were designed to elucidate the contribution of NO to cardiac myocyte damage and to determine whether NO promotes apoptosis of cardiac myocytes and infiltrating cells during acute cardiac rejection. Aminoguanidine (AG) is an inhibitor of iNOS that effects citrulline formation from arginine. ${ }^{18)}$ Treatment with AG has been shown to attenuate histological inflammatory changes in autoimmune encephalomyelitis and experimental autoimmune myocarditis. ${ }^{19,20)}$ We evaluated graft survival, histological changes and apoptotic activities in cardiac allografts with and without AG treatment.

\section{MATERIALS AND METHODS}

Animals: Male Balb / c $\left(\mathrm{H}-2^{\mathrm{d}}\right)$ mice (age 5-7 weeks, 20-25 g) and $\mathrm{C} 3 \mathrm{H} /$ He $\left(\mathrm{H}-2^{\mathrm{k}}\right)$ mice (age 5-7 weeks, 20-25 g) were obtained from Japan SLC (Shizuoka, Japan). Mice received standard chow and water and were housed under conditions approved by the Animal Welfare Committee of Shinshu University School of Medicine.

Heterotopic cardiac transplantation: Allogeneic (Balb/c to $\mathrm{C} 3 \mathrm{H} / \mathrm{He}$ ) or 
syngeneic (Balb / c to Balb / c) abdominal heterotopic cardiac transplantation was performed using a microsurgical technique as described previously. $^{21,22)}$ The hypothermic arrest time was approximately 60 minutes, and the overall surgical success rate was more than $90 \%$. Graft survival was assessed by daily palpation, and complete rejection was defined as cessation of the graft beat. ${ }^{821)}$ Recipient mice in the treatment group were given daily intraperitoneal injections of AG (Sigma, St. Louis, MO, USA) (32 $\mathrm{mg} / \mathrm{ml}$ in saline) at a dosage of $400 \mathrm{mg} / \mathrm{kg}$ starting immediately after surgery. ${ }^{20)}$

Immunohistochemistry: Mice were sacrificed on days 4, 7 and 10 after transplantation for pathological analysis. The transplanted hearts were removed from the recipient mice, and tissue specimens were embedded in OCT Compound (Sakura Finetechnical, Tokyo, Japan), rapidly frozen in liquid nitrogen, and stored at $-80^{\circ} \mathrm{C}$. Frozen sections were cut to a thickness of 6-7 $\mu \mathrm{m}$, fixed in cold acetone for 10 minutes and air-dried for more than 30 minutes. They were rinsed briefly in phosphate buffered saline (PBS) after fixation, then incubated in methanol with $0.3 \%$ hydrogen peroxide for 15 minutes. Non-specific reaction was inhibited by incubation with $5 \%$ normal goat serum for 10 minutes. The sections were incubated with antimouse iNOS antibodies (Biomol Research Laboratories, Plymouth, PA, USA), antimouse L3T4 (CD4, Pharmingen, San Diego, CA, USA), or antimouse Lyt-2 (CD8, University of Cambridge, Cambridge, UK) overnight at $4{ }^{\circ} \mathrm{C}$, washed in PBS, and exposed to biotinylated peroxidase-conjugated antibody (goat anti-rabbit or anti-rat IgG antibody) for 60 minutes at room temperature. ${ }^{22)}$ The sections were reacted with peroxidase conjugated avidin complex by use of a Vectastain Elite ABC Kit (Vector, Burlingame, CA, USA). Immune complexes were visualized with diaminobenzidine tetrahydrochloride, and the sections were counterstained with hematoxylin. The number of CD4-positive and CD8-positive infiltrating cells were counted in four random $1-\mathrm{mm}^{2}$ fields per specimen and averaged.

Histology: Sections from rejected allografts taken on days 7 and 10 and stained with standard hematoxylin and eosin (HE) were graded for acute rejection using a modification of the Billingham criteria $(0=$ no infiltrate or necrosis, $1=$ mild scattered mononuclear infiltrate or rare necrosis, $2=$ moderate infiltrate or patchy necrosis, $3=$ moderately severe infiltrate or necrosis, $4=$ severe infiltrate or necrosis, $5=$ complete rejection), and mean scores derived from two independent observers were used. ${ }^{8,23)}$

Quantitation of immunostaining: The expression of iNOS on the nontreated allografts and isografts taken on days 4, 7 and 10 and AG-treated allo- 
grafts and isografts taken on day 7 was semiquantitatively scored based on the intensity of the staining on a scale of 0 to 3 as follows: 0 , no visible staining; 1, a few cells with faint staining; 2, moderate staining; and 3, diffuse cells with intense staining. Mean scores derived from two independent observers were used. ${ }^{22)}$

Detection of apoptotic cells: Apoptotic cells were detected in situ by a TdTmediated dUTP-biotin nick end-labeling (TUNEL) method using an in situ cell death detection kit (Boehringer Mannheim Co, Indianapolis, IN, USA). Frozen sections from grafts removed on day 7 after surgery were fixed for 15 minutes in $4 \%$ paraformaldehyde, washed with PBS and permeabilized for 2 minutes with $0.1 \%$ sodium citrate, followed by incubation with TdT solution for 60 minutes at $37^{\circ} \mathrm{C}$ and sheep anti-fluorescein antibody conjugate for 30 minutes at $37^{\circ} \mathrm{C} .{ }^{11)}$ Biotinylated dUTP incorporated at the site of DNA fragmentation was visualized with Fast Red dissolved in $0.1 \mathrm{M}$ Tris-HCl, $\mathrm{pH}$ 8.2. Red stained apoptotic cells were counted in four random $1-\mathrm{mm}^{2}$ fields per specimen by an observer without knowledge of the experimental protocol, and averaged. ${ }^{13)}$ Apoptotic cells were morphologically subclassified into three groups: infiltrating cells (macrophages and mononuclear cells), cardiac myocytes, and vascular cells (endothelial cells and vascular smooth muscle cells). The ratio of apoptotic cardiac myocytes or infiltrating cells to apoptotic cells for each allograft sample was calculated by dividing the total number of each kind of apoptotic cells by that of apoptotic cells in four fields.

Analysis of DNA fragmentation: Genomic DNA was purified from frozen cardiac grafts on day 7 by a standard extraction procedure. Briefly, each graft specimen was homogenized and lysed overnight in a lysis buffer containing $100 \mathrm{mmol} / l$ Tris- $\mathrm{HCl}, \mathrm{pH} 8.0,200 \mathrm{mmol} / l \mathrm{NaCl}, 10 \mathrm{mmol} / l$ EDTA, $4 \mathrm{~mol} / l$ urea, $0.5 \% \mathrm{~N}$-Lauroylsarcosine and $0.4 \mathrm{mg} / \mathrm{m} l$ proteinase K. Lysate was extracted with phenol/chloroform, precipitated with ethanol and treated with DNase-free RNase. The resulting pellet was solubilized in Tris-EDTA buffer. Materials containing $1.5 \mu \mathrm{g}$ of DNA were electrophoresed on $1.5 \%$ agarose gel and imaged by ethidium bromide staining.

Reverse transcriptase-polymerase chain reaction (RT-PCR): The iNOS gene transcript in grafts was evaluated by RT-PCR assays as previously described. ${ }^{24)}$ RNA was extracted from cardiac grafts taken on day 4. Ten $\mu \mathrm{g}$ of RNA was prepared for reverse transcription using a cDNA cycle kit (GeneAmp PCR System 2400; Perkin Elmer) with oligo dTs used as a primer. Samples were amplified over 30 cycles with primers directed to iNOS. Primer sequences 5'-TGC CAG GGT CAC AAC TTT ACA GG 
and 3'-GGT CGA TGT CAC ATG CAG CTT GTC synthesized by Greiner Japan (Tokyo) were used. ${ }^{25}$ Products were analyzed by electrophoresis on $1.5 \%$ agarose gels. For control, cDNA preparations were analyzed for $\beta_{2}$ microglobulin.

Measurement of serum $\mathbf{N O}\left(\mathbf{N O}_{2 .}+\mathbf{N O}_{3 .}\right): \quad$ Blood samples were obtained at the time of sacrifice; i.e., on days 4,7 and 10 for nontreated allografts and isografts and on day 7 for AG-treated allografts and isografts. Serum concentrations of $\mathrm{NO}\left(\mathrm{NO}_{2-}+\mathrm{NO}_{3-}\right)$ were measured by SRL Co (Tokyo, Japan) with an automated procedure based on the Griess method. ${ }^{20)}$

Statistics: All data are expressed as mean \pm SEM. Comparison of survival rates was performed by a Kaplan-Meier survival model. Rejecting scores, $\mathrm{NO}\left(\mathrm{NO}_{2-}+\mathrm{NO}_{3-}\right)$, iNOS expression scores and apoptotic cell counts were compared using one-way ANOVA and Sheffe's method of comparison analysis. CD4-positive or CD8-positive cell counts, subclassified apoptotic cell counts and ratios of apoptotic cardiac myocytes were compared using Student's $t$ test. Statistical significance was set at $p<0.05$.

\section{RESUlts}

Cardiac graft survival: Cardiac graft survival in each group is shown in Figure 1. All nontreated control allografts were rejected within 11 days $(8.0 \pm 1.7$ days, $n=9)$. Significant prolongation of survival was observed in allografts treated with AG $(15.9 \pm 3.4$ days, $n=15)(p<0.001$ vs con-

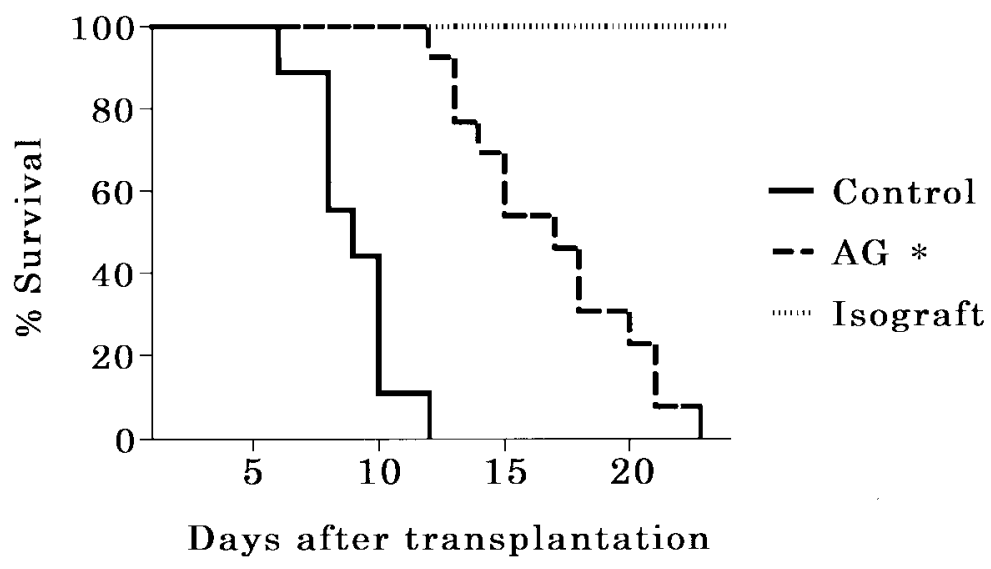

Figure 1. Survival of cardiac allografts and isografts. All allografts treated with AG kept beating for more than 11 days, whereas all nontreated control mice rejected allografts within 11 days. $* p<0.001$ vs control allograft. 
trol allograft). All nontreated isografts kept beating for more than 100 days $(n=6)$.

Histology: In nontreated allografts, scattered mononuclear cell infiltrates and myocyte necrosis were observed at day 4 and acute progression of these findings was observed at days 7 and 10 (Figure 2A). These changes were suppressed in AG-treated allografts (Figure 2B). The rejection score for allografts treated with $\mathrm{AG}$ at day $7(2.4 \pm 0.63, n=9)$ and day 10 $(2.9 \pm 0.37, n=6)$ was significantly suppressed in comparison to that for nontreated control allografts (day 7, 3.4 $\pm 0.41, n=6, p<0.005$; day 10, $4.4 \pm 0.41, n=5, p<0.001)$. Nontreated isografts taken on days 4,7 and 10 and AG-treated isografts taken on day 7 showed no pathological change in the myocardium (Figure 2C).

Immunohistochemistry: In nontreated control allografts, iNOS expression was observed in infiltrating inflammatory cells, endothelium of vessels and myocytes on day 4 and accelerated on day 7 (Figure 3A-C). The staining was stronger at sites adjacent to rich infiltrates and myocyte necrosis than
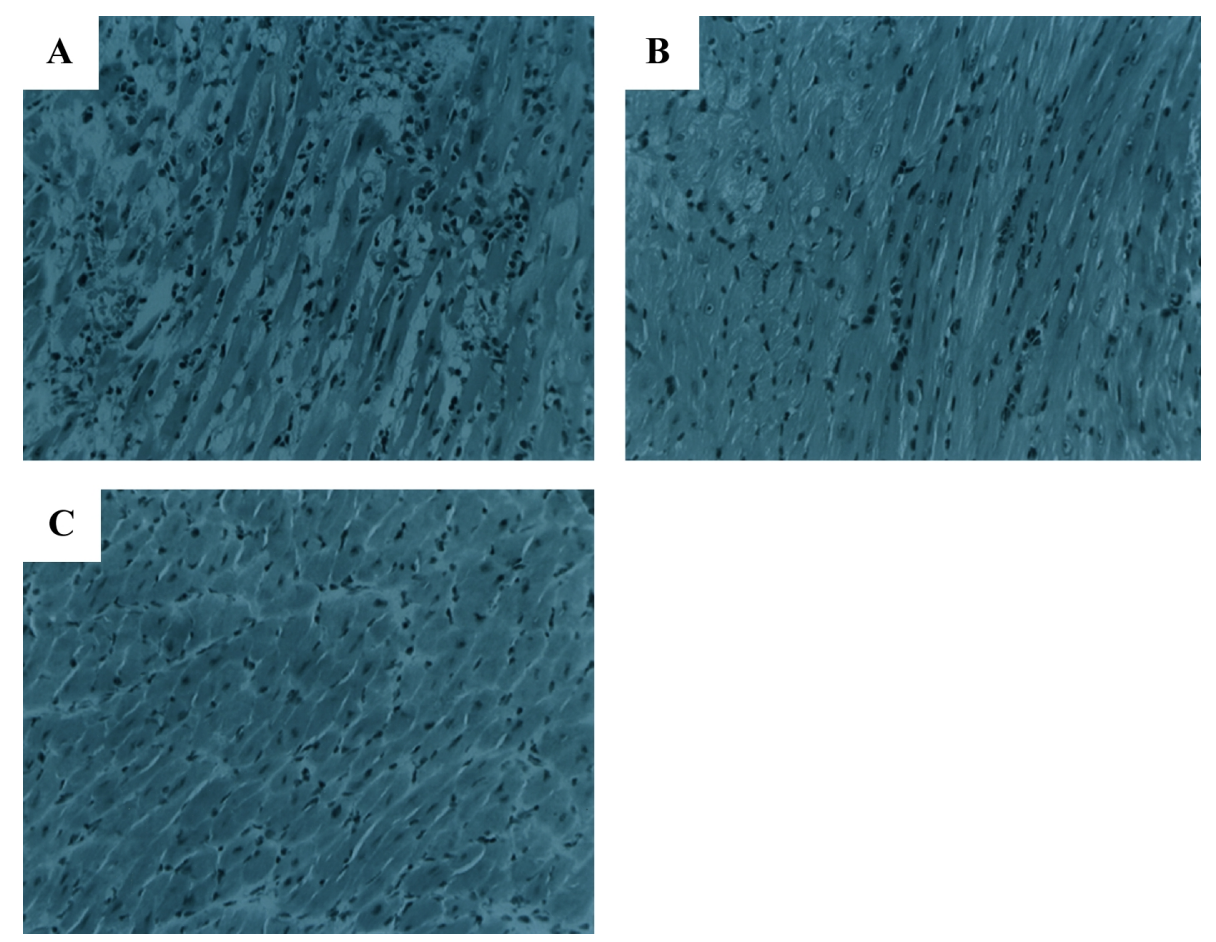

Figure 2. Hematoxylin-eosin staining of cardiac allografts (A and B) without (A) or with AG treatment (B) and an AG-treated isograft (C) at day 7. Inflammatory infiltration and myocyte necrosis were reduced in AG-treated cardiac allograft as compared with that in nontreated control allograft. (Original magnification $\times 200$ ). 
at sites with poor infiltrates. The extent of iNOS expression was reduced in AG-treated allografts in comparison to that in nontreated allografts on day 7 (Figure 3D). There was no enhancement of iNOS expression in
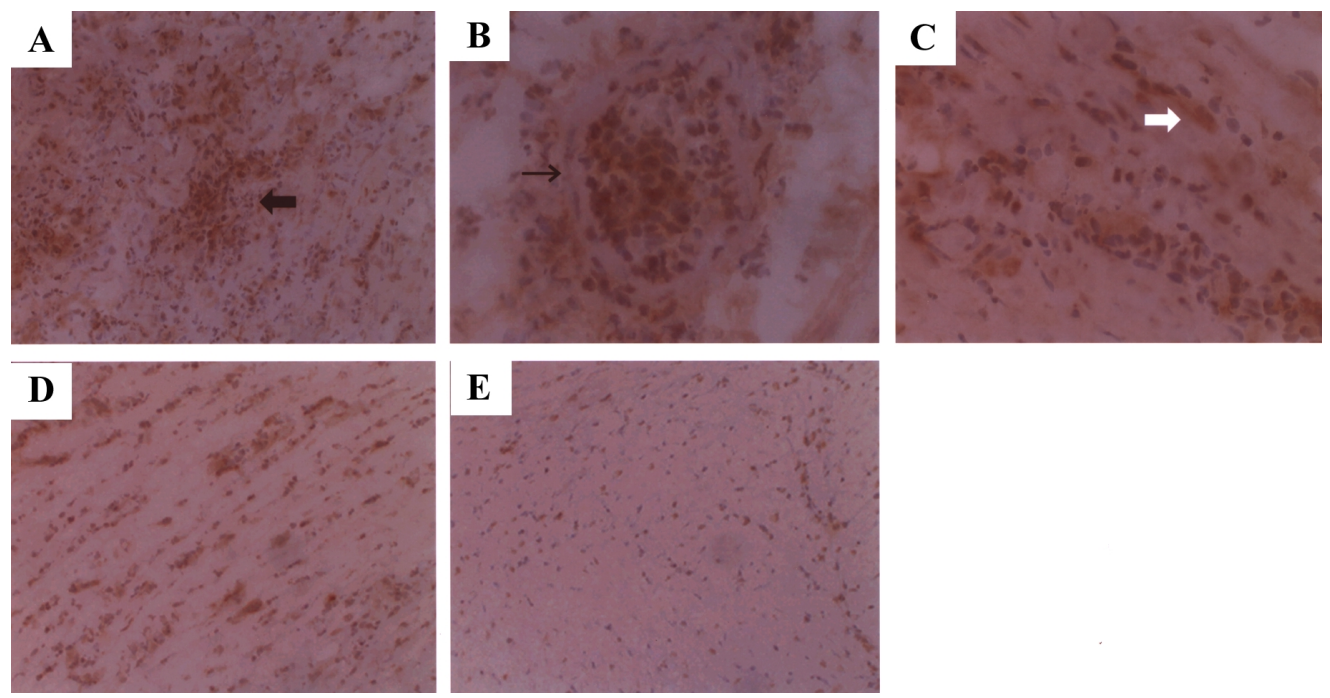

Figure 3. Immunohistochemical staining for iNOS of specimens from cardiac grafts on day 7. The upper panels show iNOS-expressing infiltrating cells (A; broad arrow) (original magnification $\times 200$ ), proliferated vascular cells (B; narrow arrow) and cardiac myocytes (C; white arrow) (original magnification $\times 400)$ in nontreated allografts. The lower panels show specimens from allografts treated with AG (D) and nontreated isografts (E) (original magnification $\times 200$ ).

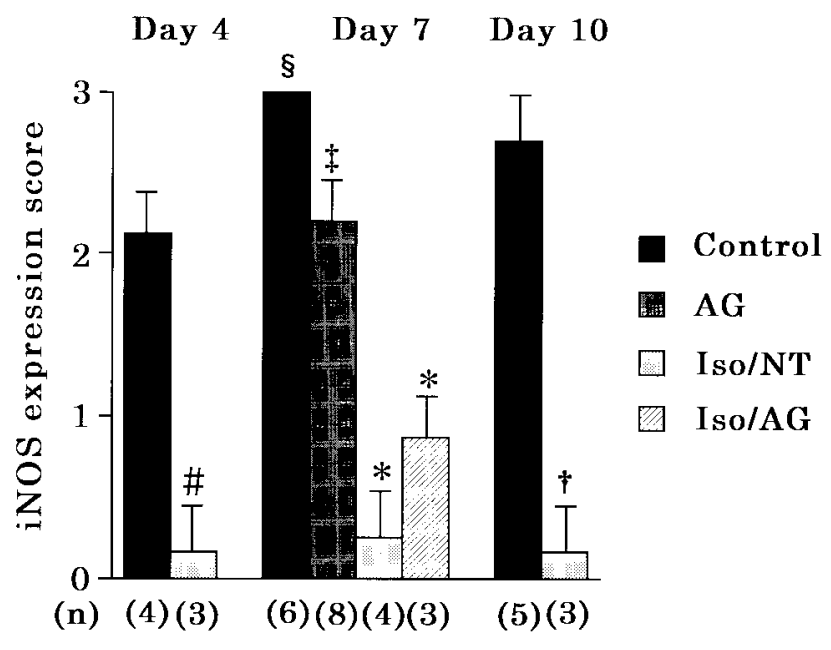

Figure 4. iNOS expression scores for AG-treated grafts at day 7 and nontreated grafts at days 4, 7 and 10 . NT $=$ no treatment. $\# p<0.0001$ vs day 4 control allograft. $\$ p<0.0005$ vs day 4 control allograft (Y-error bar for this column is 0 ). $\ddagger p<0.005$ vs day 7 control allograft. $* p<0.0001$ vs day 7 control allograft. $\dagger p<0.0001$ vs day 10 control allograft. 
isografts (Figure 3E). The iNOS expression score for AG-treated allografts was significantly lower than that for control allografts on day 7 (Figure 4). Both CD4-positive and CD8-positive cell counts were significantly lower in AG-treated allografts than in nontreated allografts (Table).

Histological analysis of apoptosis: Apoptotic cells were scarcely observed in isografts without and with AG treatment (Figure 5A, arrow head). In nontreated control allografts, apoptotic cells were detected more frequently in infiltrates and cardiac myocytes adjacent to heavy infiltrates (Figure 5B). Apoptotic cells in allografts treated with AG were significantly fewer compared to those in control allografts (Figure 5C). The total number of apoptotic cells on day 7 in nontreated control allografts, treated allografts, nontreated isografts and treated isografts were $11.5 \pm 1.7(n=6), 6.5 \pm 0.9$

Table. Number of CD4-or CD8-positive Cells in 1-mm² (average of 4 fields) in Allografts on Day 7

\begin{tabular}{llcc}
\hline & $n$ & CD4-positive cells & $\begin{array}{c}\text { CD8-positive cells } \\
\left(\text { count } / \mathrm{mm}^{2}\right)\end{array}$ \\
\hline Nontreated & 6 & $48.7 \pm 3.9$ & $28.2 \pm 2.8$ \\
AG 400 mg / kg & 9 & $28.9 \pm 4.3^{*}$ & $17.0 \pm 2.0^{*}$ \\
\hline
\end{tabular}

$* p<0.001$ vs nontreated allograft.
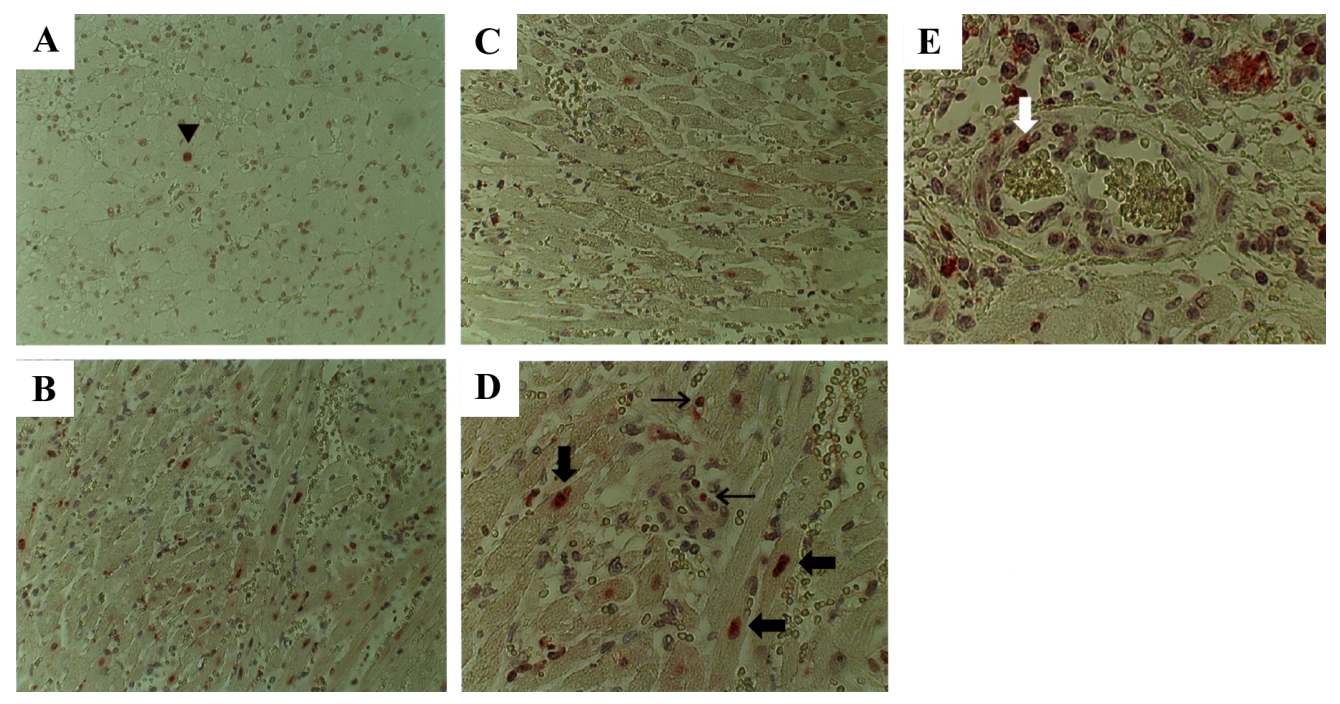

Figure 5. Apoptosis in cardiac isograft (A) and allografts (B, C, D, E) without (A, B, D, E) or with (C) AG treatment on day 7 (A, B, C: Original magnification $\times 200$; D, E: $\times 400)$. Apoptotic cells were stained in situ with the TUNEL method and morphologically classified into cardiac myocytes, infiltrating cells and vascular cells. Panel D and E are representative photomicrographs from sections of nontreated allografts showing apoptosis of cardiac myocytes (broad arrows), infiltrating cells (narrow arrows) and vascular cells (white arrow). 
$(n=9)(p<0.0001$ vs nontreated allograft $), 0.8 \pm 0.2(n=5)$ and $1.3 \pm 0.2$ count $/ \mathrm{mm}^{2}(n=4)$, respectively.

Morphological analysis showed apoptotic infiltrating cells outnumbered apoptotic cardiac myocytes. Apoptotic vascular cells were scarcely observed in control allografts or AG-treated allografts (Figure 6C). The apoptotic cardiac myocyte count in treated allografts was significantly lower than that in control allografts (Figure 6A). The ratio of apoptotic cardiac myocytes to apoptotic cells in treated allografts $(24.2 \pm 5.1 \%)$ was significantly lower than that in control allografts $(38.8 \pm 5.8 \%$, $p<0.0005)$. The apoptotic infiltrating cell count in treated allografts was also significantly lower than that in control allografts (Figure 6B). But the ratio of apoptotic infiltrating cells to apoptotic cells in treated allografts $(69.9 \pm 6.9 \%)$ was higher than that in control allografts $(59.0 \pm 5.8 \%, p<0.01)$.

DNA laddering in transplanted cardiac grafts: DNA fragmentation was not observed in any isograft. In contrast, clear nucleosomal ladders composed of multiple DNA fragments of 180,360 and 540 bps were observed in nontreated allografts. The fragmentation was diminished by treatment with AG (Figure 7).

RT-PCR: Expression of iNOS mRNA on day 4 is shown in Figure 8. iNOS mRNA was detected in nontreated and AG-treated allografts but not in any isograft.

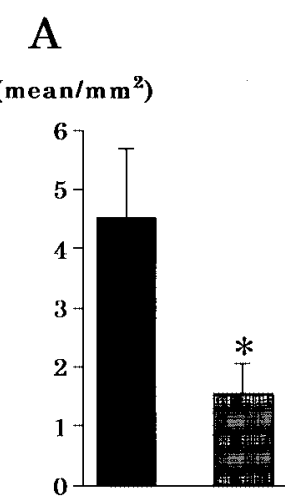

Apoptotic cardiac myocytes
B

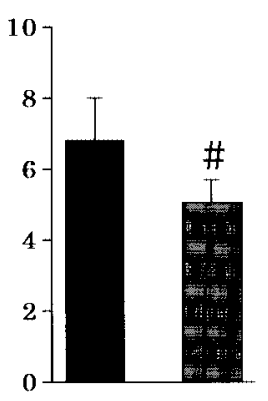

Apoptotic
C

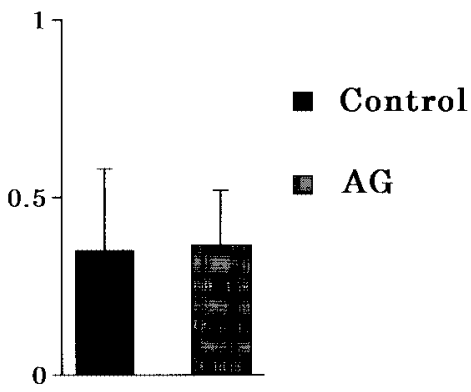

Apoptotic vascular cells

Figure 6. The number of apoptotic cells on day 7. All data are presented as TUNEL-positive cells $/ \mathrm{mm}^{2}$. AG treatment significantly decreased the apoptotic cardiac myocyte count in allografts. Apoptotic infiltrating cell count in allografts treated with AG was also less than that in control allografts. ${ }^{*} p<0.0001$ vs control allograft. $\# p<0.01$ vs control allograft. 


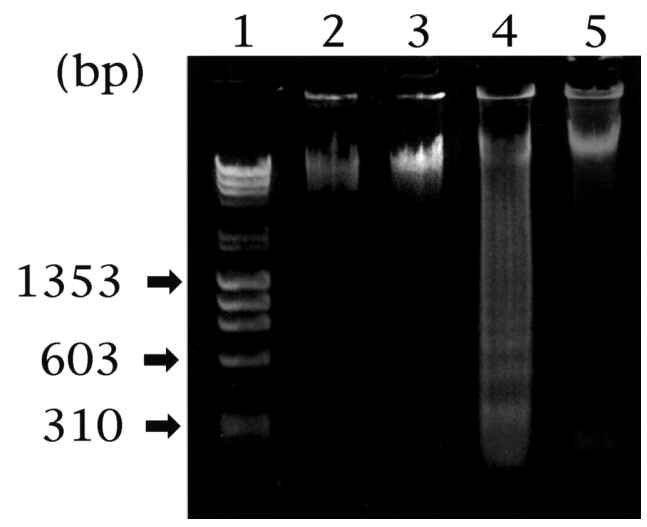

Figure 7. DNA fragmentation assay. Lane 1, base pair marker; Lane 2, nontreated isograft; Lane 3, AG-treated isograft; Lane 4, nontreated allograft; Lane 5, AG-treated allograft on day 7 .

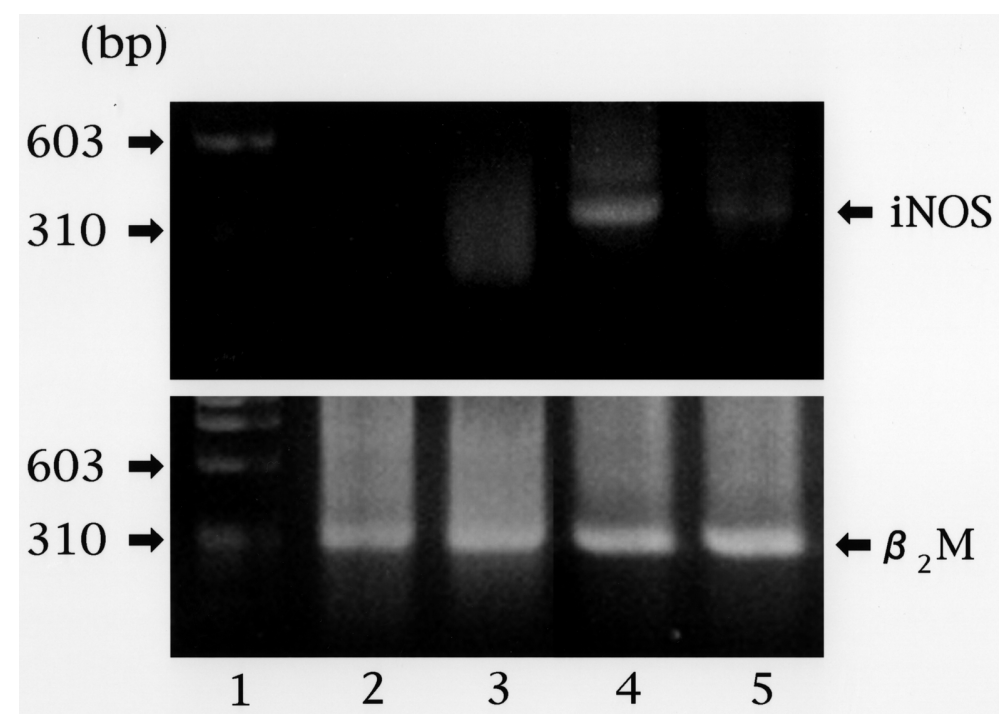

Figure 8. RT-PCR analysis of iNOS mRNA. Lane 1, base pair marker; Lane 2, nontreated isograft; Lane 3, AG-treated isograft; Lane 4, nontreated allograft; Lane 5, AGtreated allograft on day 4 . 


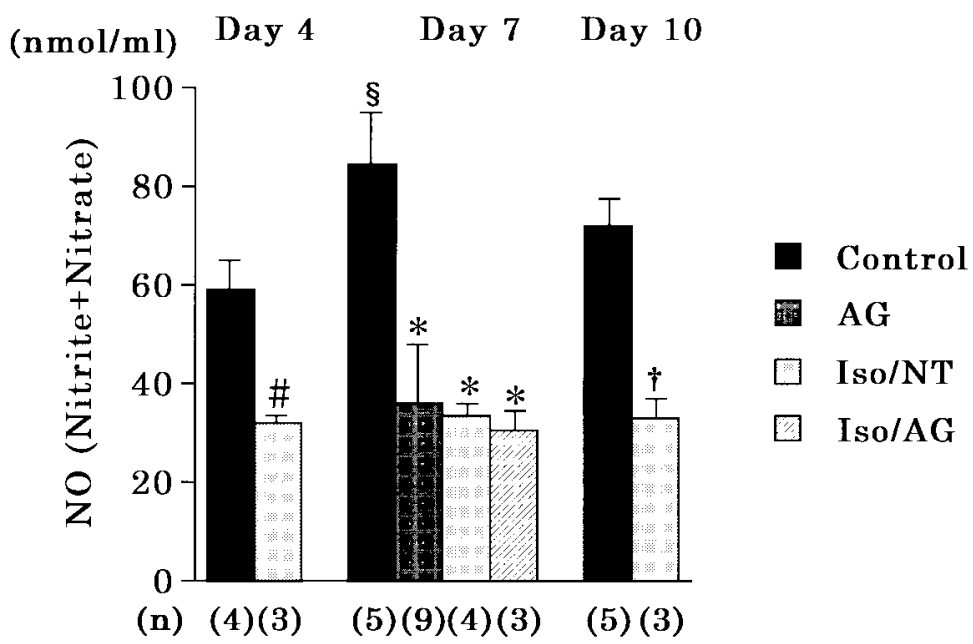

Figure 9. Serum $\mathrm{NO}\left(\mathrm{NO}_{2-}+\mathrm{NO}_{3-}\right)$ concentration $(\mu \mathrm{mol} / l)$.

$\mathrm{NT}=$ no treatment. $\# p<0.0005$ vs day 4 control allograft. $\$ p<0.05$ vs day 4 control allograft. ${ }^{*} p<0.0001$ vs day 7 control allograft. $\uparrow p<0.0005$ vs day 10 control allograft.

Serum NO $\left(\mathrm{NO}_{2-}+\mathrm{NO}_{3 .}\right)$ concentration: $\mathrm{NO}$ concentrations in the serum from nontreated isografts did not differ significantly among days 4, 7 and 10 (Figure 9). NO concentrations in the serum from nontreated control allografts peaked at day 7. At day 7, NO concentration was significantly less in AG-treated allografts and in all isografts as compared with that in nontreated control allografts.

\section{DISCUSSION}

We showed that treatment with AG, an inhibitor of iNOS, significantly prolonged allograft survival and improved pathohistological changes. This result is consistent with others using rat models. ${ }^{8,26}$ This finding indicates that excess amounts of NO can provoke myocardial injury and lead to graft failure in the rejected cardiac grafts. Possible mechanisms of NO-mediated myocardial injury have been described in previous reports. ${ }^{27,28)}$ An in vitro experiment showed that activated macrophage-derived NO induced cardiac myocyte death and that NO produced within cardiac myocytes was autotoxic. ${ }^{27)}$ NO damages cardiac allograft myocytes by inhibition of enzymes involved in mitochondrial respiration. ${ }^{28)}$ NO can also react with superoxide anion to produce the potent oxidant peroxinitrite and cause tissue damage. ${ }^{5)}$ Another mechanism in NO-mediated cell death of cardiac myocytes is apoptosis as described 
below.

Recent studies using cardiac allograft rejection in rats and human biopsy samples from rejected cardiac grafts have shown that apoptosis of cardiac myocytes is mediated at least in part by NO. ${ }^{12,13)}$ Also, apoptosis of cardiac myocytes which was induced by cytokines could be inhibited by L-NMMA, a blocker of NO synthesis. ${ }^{17)}$ L-NMMA has been shown to prolong allograft survival. ${ }^{26)} \mathrm{AG}$ is equipotent to L-NMMA as an inhibitor of iNOS and more selective for iNOS among NOS isoforms than LNMMA. ${ }^{18)}$ Therefore, AG is an appropriate agent as a selective inhibitor of iNOS to evaluate apoptotic activity in vivo. AG reduces NO synthesis by blocking the production of L-citrulline and NO from L-anginine catalyzed by iNOS. ${ }^{18)}$ This inhibitory effect of AG for the downstream below iNOS should explain the discrepancy that NO concentrations in the serum were more strongly suppressed than reduction in the iNOS expression score. We showed that apoptosis detected by TUNEL assay and DNA laddering in rejecting cardiac allograft could be reduced by AG treatment. This reduction predominantly affected cardiac myocytes rather than infiltrating leukocytes or vascular cells. This finding indicates that NO induces apoptosis of cardiac myocytes more intensively than that of other cell types in rejecting allografts. Susceptibility to apoptosis may differ between these cell types. Cardiac myocyte DNA is especially susceptible to peroxinitrite, which is produced by NO. ${ }^{1729)}$ In contrast, apoptosis of infiltrating leukocytes could be mediated by mechanisms independent to the NO pathway. ${ }^{17,30)}$ We therefore speculate that NO-mediated myocardial apoptosis is a major cause of myocardial cell death in rejected cardiac grafts.

In our experiment, the migration of infiltrating cells was significantly attenuated in the AG-treated allografts. The histological score reflecting acute rejection was less in this group. CD4-positive and CD8-positive cells were equally reduced. This finding may not be associated with direct inhibition of inflammatory cell migration by AG, since the effects of AG on $\mathrm{T}$ cell function or cell migration have not been shown. In vitro studies also have shown that NO inhibits proliferation of allospecific $\mathrm{T}$ lymphocytes. $^{6,7)}$ It is possible that apoptotic rejecting cardiac myocytes could release cytokines which might further extend the area of myocardial damage by various factors including NO. We speculate that AG can inhibit this process by attenuation of inflammation with reduction of NO production at an early stage of acute rejection. This mechanism should be examined in future experiments.

We have demonstrated that a reduction in NO synthesis by AG treat- 
ment decreased apoptosis of cardiac allograft cells, especially that of cardiac myocytes. The proapoptotic effect of NO on the transplanted heart is cell-type dependent. This reduction was associated with prolonged cardiac allograft survival. Thus, NO produced by iNOS in this situation certainly promotes cardiac allograft failure. iNOS inhibitors could be useful in suppression of cardiac myocyte apoptosis and could be clinically beneficial in myocyte protection after cardiac transplantation. Further studies are required to elucidate the appropriate conditions in which such agents should be used in patients.

\section{ACKNOWLEDGMENT}

This study was supported by a Research Grant for Immunology, Allergy and Organ Transplant from the Japanese Ministry of Health and Welfare, Ministry of Science, Culture, Sports and Education, and grants from the Uehara Foundation. We would like to thank Midori Oike and Rie Shiohara for their technical assistance.

\section{REFERENCES}

1. Yang X, Chowdhury N, Cai B, et al. Induction of myocardial nitric oxide synthase by cardiac allograft rejection. J Clin Invest 1994; 94: 714-21.

2. Winlaw DS, Schyvens CG, Smythe GA, et al. Urinary nitrate excretion is a non-invasive indicator of acute cardiac allograft rejection and nitric oxide production in the rat. Transplantation 1994; 58: 1031-6.

3. Worrall NK, Chang K, Suau GM, et al. Inhibition of inducible nitric oxide synthase prevents myocardial and systemic vascular barrier dysfunction during early cardiac allograft rejection. Circ Res 1996; 78: 769-79.

4. Moncada S, Palmer RMJ, Higgs EA. Nitric oxide: physiology, pathophysiology, and pharmacology. Pharmacol Rev 1991; 43: 109-42.

5. Beckman JS, Koppenol WH. Nitric oxide, superoxide, and peroxynitrite: the good, the bad, and the ugly. Am J Physiol 1996; 271 (Cell Physiol 40): C1424-37.

6. Langrehr JM, Dull KE, Ochoa JB, et al. Evidence that nitric oxide production by in vivo allosensitized cells inhibits the development of allospecific CTL. Transplantation 1992; 53: 632-40.

7. Gregory SH, Sagnimeni AJ, Wing EJ. Arginine analogues suppress antigen-specific and non-specific T lymphocyte proliferation. Cell Immunol 1994; 153: 527-32.

8. Worrall NK, Lazenby WD, Misko TP, et al. Modulation of in vivo alloreactivity by inhibition of inducible nitric oxide synthase. J Exp Med 1995; 181: 63-70.

9. Albina JE, Cui S, Mateo RB, Reichner JS. Nitric oxide-mediated apoptosis in murine peritoneal macrophages. J Immunol 1993; 150: 5080-5.

10. Fehsel K, Kroncke KD, Meyer KL, Huber H, Wahn V, Kolb-Bachofen V. Nitric oxide induces apoptosis in mouse thymocytes. J Immunol 1995; 155: 2858-65.

11. Iwashina M, Shichiri M, Marumo F, Hirata Y. Transfection of inducible nitric oxide synthase gene causes apoptosis in vascular smooth muscle cells. Circulation 1998; 98: 1212-8.

12. Szabolcs M, Michler RE, Yang X, et al. Apoptosis of cardiac myocytes during cardiac allograft rejection: relation to induction of nitric oxide synthase. Circulation 1996; 94: 1665-73.

13. Szabolcs MJ, Ravalli S, Minanov O, Sciacca RR, Michler RE, Cannon PJ. Apoptosis and increased expression of inducible nitric oxide synthase in human allograft rejection. Transplantation 1998; 65: 804-12. 
14. Dimmeler S, Haendeler J, Nehls M, Zeiher AM. Suppression of apoptosis by nitric oxide via inhibition of interleukin- $\beta$-converting enzyme (ICE) -like and cysteine protease protein (CPP) -32-like proteases. J Exp Med 1997; 185: 601-7.

15. Kim YM, Talanian RV, Billiar TR. Nitric oxide inhibits apoptosis by preventing increases in caspase-3-like activity via two distinct mechanisms. J Biol Chem 1997; 272: 31138-48.

16. Hebestreit H, Dibbert B, Balatti I, et al. Disruption of Fas receptor signaling by nitric oxide in eosinophils. J Exp Med 1998; 187: 415-25.

17. Ing DJ, Zang J, Dzau VJ, Webster KA, Bishopric NH. Modulation of cytokine-induced cardiac myocyte apoptosis by nitric oxide, Bak and Bcl-x. Circ Res 1999; 84: 21-33.

18. Misko TP, Moore WM, Kasten TP, et al. Selective inhibition of the inducible nitric oxide synthase by aminoguanidine. Eur J Pharmacol 1993; 233: 119-25.

19. Cross AH, Misko TP, Lin RF, Hickey WF, Trotter JL, Tilton RG. Aminoguanidine, an inhibitor of inducible nitric oxide synthase, ameliorates experimental autoimmune encephalomyelitis in SJL mice. J Clin Invest 1994; 93: 2684-90.

20. Ishiyama S, Hiroe M, Nishikawa $\mathrm{T}$, et al. Nitric oxide contributes to the progression of myocardial damage in experimental autoimmune myocarditis in rats. Circulation 1997; 95: 489-96.

21. Isobe M, Yagita H, Okumura K, Ihara A. Specific acceptance of cardiac allograft after treatment with antiICAM-1 and anti-LFA-1. Science 1992; 255: 1125-7.

22. Suzuki J, Isobe M, Yamazaki S, Horie S, Okubo Y, Sekiguchi M. Inhibition of accelerated coronary atherosclerosis with short-term blockade of intercellular adhesion molecule-1 and lymphocyte function-associated antigen-1 in a heterotopic murine model of heart transplantation. J Heart Lung Transplant 1997; 16: 1141-8.

23. Billingham ME. Diagnosis of cardiac rejection by endomyocardial biopsy. J Heart Transplant 1981; 1: 25-30.

24. Yamazaki S, Isobe M, Suzuki J, et al. Role of selectin-dependent adhesion in cardiac allograft rejection. J Heart Lung Transplant 1998; 17: 1007-16.

25. Russell ME, Wallace AF, Wyner LR, Newell JB, Karnovsky MJ. Upregulation and modulation of inducible nitric oxide synthase in rat cardiac allografts with chronic rejection and transplant arteriosclerosis. Circulation 1995; 92: 457-64.

26. Winlaw DS, Schyvens CG, Smythe GA, et al. Selective inhibition of nitric oxide production during cardiac allograft rejection causes a small increase in graft survival. Transplantation 1995; 60: 77-82.

27. Pinsky DJ, Cai B, Yang X, Rodriguez C, Sciacca RR, Cannon PJ. The lethal effects of cytokine-induced nitric oxide on cardiac myocytes are blocked by nitric oxide synthase antagonism or transforming growth factor $\beta$. $\mathrm{J}$ Clin Invest 1995; 95: 677-85.

28. Lancaster JR Jr, Langehr JM, Bergonia HA, Murase N, Simmons RL, Hoffman RA. EPR detection of heme and non-heme iron-containing protein nitrosylation by nitric oxide during rejection of rat heart allograft. J Biol Chem 1992; 267: 10994-8.

29. Nguyen T, Brunson D, Crespi CL, Penman BW, Wishnok JS, Tannenbaum SR. DNA damage and mutation in human cells exposed to nitric oxide in vitro. Proc Natl Acad Sci USA 1992; 89: 3030-4.

30. Zheng L, Fisher G, Miller RE, Peschon J, Lynch DH, Lenardo MJ. Induction of apoptosis in mature T cells by tumor necrosis factor. Nature 1995; 377: 348-51. 